OPEN ACCESS

Edited by:

Filippo M. Sarullo,

Ospedale Buccheri la Ferla

Fatebenefratelli, Italy

Reviewed by:

Micha Tobias Maeder,

Kantonsspital St. Gallen, Switzerland

Alberto Palazzuoli,

University of Siena, Italy

${ }^{*}$ Correspondence:

Dachun XU

xdc77@tongji.edu.cn

Specialty section:

This article was submitted to Heart Failure and Transplantation, a section of the journal

Frontiers in Cardiovascular Medicine

Received: 14 January 2021 Accepted: 07 April 2021

Published: 12 May 2021

Citation:

Ma T, Su Y, Song J and Xu D (2021) Treatment of Heart Failure With Mid-Range Ejection Fraction: A Summary of Current Evidence. Front. Cardiovasc. Med. 8:653336.

doi: 10.3389/fcvm.2021.653336

\section{Treatment of Heart Failure With Mid-Range Ejection Fraction: A Summary of Current Evidence}

\author{
Teng $\mathrm{Ma}^{1}$, Yang $\mathrm{Su}^{1}$, Jing Song ${ }^{2}$ and Dachun $\mathrm{Xu}^{1 *}$ \\ ${ }^{1}$ Department of Cardiology, Shanghai Tenth People's Hospital, Tongji University School of Medicine, Shanghai, China, \\ ${ }^{2}$ Department of Cardiology, The Second Affiliated Hospital and Yuying Children's Hospital, Wenzhou Medical University, \\ Wenzhou, China
}

Heart failure (HF) is a complex syndrome causing heavy burden in public health, and the modern objective assessment of it is based on the left ventricular ejection fraction (LVEF). In 2016, the European Society of Cardiology classified the "gray area" in HF with LVEF of $40-49 \%$ as a new HF phenotype (HFmrEF) in an attempt to uncover the specific characteristics and treatment of these patients, which might recover or worsen to HFpEF or HFrEF, respectively, or conversely from these two subtypes. Up to now, many studies have demonstrated that patients with HFmrEF would possibly gain more benefits from some targeted therapies with HFrEF than those with HFpEF. This review summarizes what is known about the findings in the treatment of HFmrEF and discusses what should be done to better define the peculiar HF phenotype in the future.

Keywords: heart failure, HFmrEF, HFPEF, treatment, review

\section{INTRODUCTION}

Heart failure (HF) is a complex clinical syndrome characterized by reduced cardiac output and/or elevated filling pressures at rest or with exertion. Recognizing different heart failure (HF) subtypes is so important, not only because it broadly frames differences in the underlying pathophysiology, but also because each of the HF subtypes presents different outcomes in therapeutic approaches $(1,2)$. The modern management of heart failure (HF) is primarily guided by clinical objective assessments of left ventricular ejection fraction (LVEF), which has been proven to be an efficacious predictive method of adverse outcomes even in patients without symptomatic HF.

In 2016, the European Society of Cardiology classified HF with mid-range ejection fraction (HFmrEF) as LVEF of $40-49 \%$ (3), which has often been considered a "gray" area in HF, as HFmrEF remains insufficiently characterized compared with the HFrEF and HFpEF subtypes in the past years. This new classification, as acknowledged in the guidelines, is an attempt to stimulate research and resolve critical clinical questions, rather than a true admittance of an independent phenotype different from the other groups. And as expected, there has been research on the clinical entity of HFmrEF in recent years, which presented us with expanding insights into epidemiology, pathophysiology, clinical characteristics, morbidity and mortality, and treatment for patients with HFmrEF. Clinical trial data suggest a HFmrEF prevalence of $14-24 \%$ among the overall HF population (4-8).

The EF may change with treatment and over time, and the heterogeneity is deduced by the different etiology of HF. A considerable number of patients transition to either HFrEF or HFpEF while on treatment. Coronary artery disease seems to be common, and it seems to play a critical 
role for worsening from HFpEF to HFmrEF or from HFmrEF to HFrEF. As there are a flurry of findings that HFmrEF specifies the aspects resembling the other two HF categories, which provide us with a feasible explanation of the controversies about why some researchers thought HFmrEF was a "transition phase" of HFrEF and HFpEF. This raises a question of which potential therapies thus far reserved for patients with HFrEF may be beneficial in those with intermediate LVEF.

As there are difficulties in the enrollment of patients with HFmrEF, there have been no randomized controlled trials (RCTs) dedicated to evaluate the effect of therapy. Therefore, we could only find some information on the overlap between HFmrEF and other groups, as we did from the CHARM, TOPCAT, and PARAGON clinical trials, which all showed an effect of different drugs in the lower end of the LVEF spectrum included in these studies, such as $40-50 \%$ or $45-50 \%$. We have made some progress in understanding the treatment efficacy of neurohormonal antagonists, including angiotensin-converting enzyme inhibitors/ACEI, angiotensin receptor blockers/ARB, beta-blockers, and mineralocorticoid receptor antagonists/MRA, in patients with HFmrEF. In this review, we will present an overview about the updated therapies for patients with HFmrEF.

\section{ANGIOTENSIN-CONVERTING ENZYME INHIBITORS (ACEI) AND ANGIOTENSIN RECEPTOR BLOCKERS (ARB)}

In a post-hoc analysis of a randomized clinical trial, named the CHARM program, in which the 7,598 patients with available integer digit EF were divided into three parts: HFrEF, HFmrEF, and HFpEF (9), the authors evaluated the treatment effect of candesartan in patients with HFmrEF, and found there was a smaller risk of primary outcome [HR: 0.76; 95\% CI (0.61-0.96); $p=0.02$ ] and recurrent HF hospitalization [HR: 0.48, 95\% CI $(0.33-0.70), p<0.001]$ in the treatment group during the mean follow-up of 2.9 years. It is notable that the treatment efficacy of candesartan was constant at a lower EF and generally began to decline at $\mathrm{EF}>50 \%$. However, in the randomized controlled I-PRESERVE trial with LVEF >45\% (10), there was no difference between the irbesartan treatment group compared with the placebo group, though the average LVEF was higher in this trial (mean LVEF, 59\%) compared with the CHARMpreserved trial (mean LVEF, 54\%). In an observational study (11), the OPTIMIZE-HF trial, HF patients with LVEF $>40 \%$ also did not benefit from ACEI/ARB therapy in the first 60 to 90 days of follow-up.

\section{BETA-BLOCKERS}

Cleland et al. (12) used a meta-analysis of randomized controlled trials to demonstrate that beta-blockers may reduce $\mathrm{CV}$ death in HFmrEF patients in sinus rhythm compared with placebo [HR 0.48; 95\% CI (0.24-0.97); $p=0.04$ ] and improve left ventricular systolic function with a higher LVEF using data from double-blind, randomized, placebo-controlled trials. Similar to the outcomes above, several observational studies suggested that beta-blockers treatment may have benefits in cardiovascular outcomes in the HFmrEF population. In the multicenter prospective registry CHART-2 cohort (13), beta-blocker use was associated with reduced mortality among those with HFmrEF. Similarly, in the Swedish Heart Failure Registry (6), betablockers were associated with reduced mortality only in the presence of CVD (HR up to 1 year 0.74, 95\% CI 0.59-0.92), nevertheless, ACEI/ARBs and statins were associated with lower 1-year all-cause mortality with or without CVD. However, in the OPTIMIZE-HF trial (14), initiation of beta-blockers did not show improved outcomes in the HF patients with $\mathrm{LVEF}>40 \%$, and another study also revealed that there were no improvements in all-cause mortality in those with EF $>40 \%$ (15).

\section{MINERALOCORTICOID RECEPTOR ANTAGONISTS (MRAs)}

A study used data from a randomized controlled trial called TOPCAT (16) to assess the relationship between efficacy and outcome of spironolactone and LVEF, found that LVEF modified the treatment efficacy of spironolactone, those with LVEF between 45 and $50 \%$ had a lower primary outcome [HR 0.72 , 95\% CI $(0.50,1.05)]$ and HF hospitalization [HR 0.76, 95\% CI $(0.46,1.27)]$. Along with this, in a prospective study (17), during a mean follow-up of 2.2 years, Enzan et al. found that patients with spironolactone had a lower incidence rate of primary outcome (all-cause death and or HF rehospitalization) than those without it [RR 0.61, 95 CI (0.44-0.86), $P=0.004$ ].

\section{SACUBITRIL/VALSARTAN}

There were 4,822 patients with LVEF > 45\% who were randomly assigned to sacubitril/valsartan or valsartan groups in the PARAGON-HF trial (18). The primary composite outcome of total hospitalizations for heart failure and death from cardiovascular causes had no statistical significance between the two groups. Although statistically non-significant, it is noticeable that sacubitril/valsartan had a lower rate of hospitalization for heart failure than valsartan alone (rate ratio $0.87,95 \% \mathrm{CI}$ $0.75-1.01, p=0.06$ ). And of the 12 pre-specified subgroups, two showed a benefit in patients with an ejection fraction in the lower part (45-57\%) of the study and in women. Along with this, Solomon and colleagues (19) combined data from the PARADIGM-HF (LVEF eligibility $\leq 40 \% ; n=8,399$ ) and PARAGON-HF trials, as the two studies had similarities in many aspects such as eligibility criteria, similar control groups (enalapril or valsartan, respectively), and outcome assessment. The pooled analysis containing a total cohort of 13,195 patients suggested that patients with LVEF lower than normal, including HFmrEF or borderline ejection fraction, would possibly benefit, particularly in the combined end-point of cardiovascular mortality and first hospitalization for HF, from sacubitril/valsartan compared with RAS inhibition. And these therapeutic benefits appeared to extend to a higher LVEF range in women compared with men. A study suggested that combination use of sacubitril/valsartan rather than valsartan 
TABLE 1 | Overview of the main studies investigating patients with HFmrEF.

\begin{tabular}{|c|c|c|c|c|c|}
\hline References & Study type & Inclusion criteria & LVEF & $\begin{array}{l}\text { Patient } \\
\text { number }\end{array}$ & Outcome for HFmrEF \\
\hline Lund et al. (9) & $\begin{array}{l}\text { Post-hoc analysis of } \\
\text { randomized trial }\end{array}$ & $\begin{array}{l}\text { Patients enrolled in CHARM } \\
\text { program }\end{array}$ & Full spectrum & 7,599 & $\begin{array}{l}\text { Primary outcome for candesartan vs. placebo: }[\mathrm{HR} \text { : } \\
0.76,95 \% \mathrm{Cl}(0.61,0.96), p=0.02] \\
\text { recurrent } \mathrm{HF} \text { hospitalization: }[\mathrm{HR}: 0.48,95 \% \mathrm{Cl} \\
(0.33,0.70), p<0.001]\end{array}$ \\
\hline Solomon et al. (16) & $\begin{array}{l}\text { Post-hoc analysis of } \\
\text { randomized trial }\end{array}$ & $\begin{array}{l}\text { Patients with HF and LVEF } \\
\geq 45 \% \text { enrolled in TOPCAT }\end{array}$ & $>45 \%$ & 3,444 & $\begin{array}{l}\text { Primary outcome for spironolactone vs. placebo: } \\
\text { [LVEF < 50\%,HR: } 0.72,95 \% \mathrm{Cl}(0.50,1.05) \\
p=0.046] \\
\text { heart failure hospitalization [LVEF < 50\%, HR: } 0.76 \text {, } \\
95 \% \mathrm{Cl}(0.46,1.27), p=0.039]\end{array}$ \\
\hline Cleland et al. (12) & $\begin{array}{l}\text { Meta-analysis of } \\
\text { randomized controlled } \\
\text { trials }\end{array}$ & $\begin{array}{l}\text { Included all patients with } \\
\text { baseline LVEF and an } \\
\text { electrocardiogram (ECG) } \\
\text { that showed either sinus } \\
\text { rhythm or AF/atrial flutter }\end{array}$ & Full spectrum & 14,262 & $\begin{array}{l}\text { Beta-blockers may reduce CV death in HFmrEF } \\
\text { patients in sinus rhythm compared with placebo } \\
\text { [HR: } 0.48,95 \% \mathrm{Cl}(0.24,0.97), p=0.04]\end{array}$ \\
\hline Solomon et al. (18) & $\begin{array}{l}\text { Post-hoc analysis of } \\
\text { randomized trial }\end{array}$ & $\begin{array}{l}\text { Patients with HF and LVEF } \\
\geq 45 \% \text { enrolled in } \\
\text { PARAGON-HF }\end{array}$ & $>45 \%$ & 4,822 & $\begin{array}{l}\text { Primary events for sacubitril-valsartan vs. valsartan: } \\
{[R R: 0.87,95 \% \mathrm{Cl}(0.75,1.01), p=0.06]}\end{array}$ \\
\hline $\begin{array}{l}\text { Abdul-Rahim et al. } \\
\text { (20) }\end{array}$ & $\begin{array}{l}\text { Post-hoc analysis of } \\
\text { randomized trial }\end{array}$ & $\begin{array}{l}\text { Patients enrolled in DIG. HF } \\
\text { patients with LVEF } \leq 45 \% \\
\text { and were in normal sinus } \\
\text { rhythm ( } 6,800 \text { patients). HF } \\
\text { patients with LVEF > } 45 \% \\
\text { were enrolled in an ancillary } \\
\text { trial ( } 988 \text { patients) }\end{array}$ & Full spectrum & 7,788 & $\begin{array}{l}\text { Digoxin had an intermediate effect in HFmrEF [HR: } \\
0.80,95 \% \mathrm{Cl}(0.63,1.03)] \text { compared with HFrEF } \\
\text { and HFpEF; } \\
\text { the composite of HF death or HF hospitalization } \\
\text { [HR: } 0.83,95 \% \mathrm{Cl}(0.66,1.05)]\end{array}$ \\
\hline Massie et al. (10) & $\begin{array}{l}\text { Randomized controlled } \\
\text { trial }\end{array}$ & $\begin{array}{l}\text { Patients with HF and LVEF } \\
\geq 45 \% \text { in I-PRESERVE }\end{array}$ & $\geq 45 \%$ & 4,128 & $\begin{array}{l}\text { The primary outcome in the irbesartan group vs. the } \\
\text { placebo group: [HR: } 0.95,95 \% \mathrm{Cl}(0.86,1.05) \text {, } \\
p=0.35) \text {; } \\
\text { the secondary outcome: rates of death from any } \\
\text { cause in the irbesartan group and the placebo } \\
\text { group: [HR: } 1.00,95 \% \mathrm{Cl}(0.88,1.14), p=0.98] \text {; } \\
\text { rates for protocol-specified hospitalization: [HR: } \\
0.95,95 \% \mathrm{Cl}(0.85,1.08), p=0.44]\end{array}$ \\
\hline Enzan et al. (17) & $\begin{array}{l}\text { Multicenter prospective } \\
\text { registry }\end{array}$ & $\begin{array}{l}\text { Patients with HF and with } \\
\text { LVEF of } \geq 40 \text { and }<50 \% \\
\text { from JCARE-CARD }\end{array}$ & $40-50 \%$ & 457 & $\begin{array}{l}\text { Primary outcome for spironolactone vs. placebo: } \\
\text { [IRR: } 0.61,95 \% \mathrm{Cl}(0.44,0.86) ; p=0.004] \text { ] } \\
\text { composite of all-cause death or HF rehospitalization } \\
\text { [adjusted HR: } 0.63,95 \% \mathrm{Cl}(0.44,0.90), P=0.010 \text { ] }\end{array}$ \\
\hline Tsuji et al. (13) & $\begin{array}{l}\text { Multicenter prospective } \\
\text { registry }\end{array}$ & $\begin{array}{l}\text { Patients with HF and LVEF } \\
\geq 45 \% \text { enrolled in CHART-2 }\end{array}$ & Full spectrum & 3,480 & $\begin{array}{l}\text { Beta-blockers were positively associated with } \\
\text { HFmrEF [HR: } 0.57,95 \% \mathrm{Cl}(0.37,0.87), p=0.010] \text {; } \\
\text { diuretics were negatively associated with improved } \\
\text { mortality in HFmrEF [HR: } 2.01,95 \% \mathrm{Cl}(1.24,3.28) \text {, } \\
p=0.004]\end{array}$ \\
\hline Fonarow et al. (11) & Prospective registry & $\begin{array}{l}\text { Patients with HF and LVEF } \\
\geq 40 \% \text { and left ventricular } \\
\text { systolic dysfunction (LVSD) } \\
\text { with reduced EF enrolled in } \\
\text { OPTIMIZE-HF }\end{array}$ & $\geq 40 \%$ & 41,267 & $\begin{array}{l}\text { 60- to } 90 \text {-day mortality: [HR: } 1.141,95 \% \mathrm{Cl}(0.812 \text {, } \\
\text { 1.603), } p=0.447] \text { and rehospitalization rates }[\mathrm{HR} \text { : } \\
\text { 0.909, } 95 \% \mathrm{Cl}(0.692,1.196), p=0.497] \text { for } \\
\text { ACEI/ARB; } \\
60 \text { - to } 90 \text {-day mortality: [HR: } 1.209,95 \% \mathrm{Cl}(0.872 \text {, } \\
\text { 1.875), } p=0.255] \text { and rehospitalization rates [HR: } \\
0.923,95 \% \mathrm{Cl}(0.723,1.179), p=0.523] \text { for } \\
\text { beta-blockers }\end{array}$ \\
\hline Lund et al. (9) & $\begin{array}{l}\text { Nationwide prospective } \\
\text { registry }\end{array}$ & $\begin{array}{l}\text { Patients with HF enrolled in } \\
\text { SwedeHF }\end{array}$ & Full spectrum & 51,060 & $\begin{array}{l}\text { Beta-blockers use and } 1 \text {-year mortality in HFmrEF: } \\
\text { mortality was reduced in HFmrEF with CAD [HR up } \\
\text { to } 1 \text { year } 0.74,95 \% \mathrm{Cl}(0.59,0.92)] \text { but not in } \\
\text { HFmrEF without CAD [HR 0.99, 95\% } \mathrm{Cl}(0.78 \text {, } \\
1.26)] \text {; } \\
\text { angiotensin-converting enzyme inhibitors } \\
\text { (ACEI)/angiotensin receptor blockers (ARBs)/statins } \\
\text { were associated with reduced risk in all HFmrEF } \\
\text { groups with or without CAD (all } p \leq 0.004)\end{array}$ \\
\hline
\end{tabular}

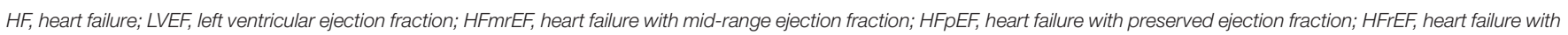

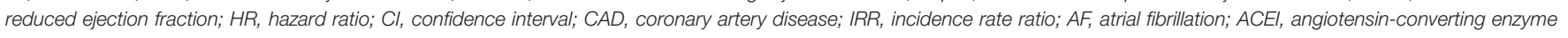
inhibitors; ARBs, angiotensin receptor blockers. 
TABLE 2 | Medical therapy in heart failure.

\begin{tabular}{|c|c|c|c|c|c|c|c|}
\hline & ACEI & ARB & Beta-blocker & MRA & ARNI & SGLT2I & Diuretic \\
\hline HFrEF & $\uparrow \uparrow$ & $\uparrow \uparrow$ & $\uparrow \uparrow$ & $\uparrow \uparrow$ & $\uparrow \uparrow$ & $\uparrow \uparrow$ & $?$ \\
\hline HFmrEF & $?$ & $\uparrow$ & $\uparrow$ & $\uparrow$ & $\uparrow$ & $?$ & $?$ \\
\hline HFpEF & $x$ & $\uparrow$ & $x$ & $\uparrow$ & $\uparrow$ & $?$ & $?$ \\
\hline
\end{tabular}

$\uparrow \uparrow:$ Proven cardiovascular benefit.

$\uparrow:$ Potential cardiovascular benefit.

x: No cardiovascular benefit.

?: Uncertain cardiovascular benefit.

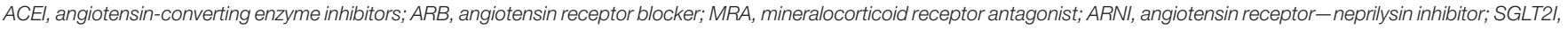

sodium glucose cotransporter 2 inhibitors.

alone with MRA appeared to be associated with a lesser decline of renal function and no increase in severe hyperkalemia in patients with LVEF $>45 \%$ in the PARAGON-HF trial, which would provide us with a new insight of benefit of combined therapy (21). In the PARALLAX trial (22), randomizing 2,572 patients with a LVEF of $>40 \%$, NT-proBNP was significantly reduced in the sacubitril/valsartan group after 12 weeks vs. individualized medical therapy, and was associated with a reduction of left atrial size. But it is noticeable that there was a significantly difference in terms of NTproBNP cut-off diastolic dysfunction analysis and comorbidities compared with other trials. There was a lower risk of worsening renal function with sacubitril/valsartan in $\mathrm{HF}$ patients with LVEF $>40 \%$ than those with LVEF $\leq 40 \%$ (23), according to a systematic review and meta-analysis of randomized controlled trials. Excitingly, the FDA panel has supported the expanded indication for sacubitril/valsartan, which would allow it to be a treatment for certain patients with HFpEF, and it is possible that sacubitril/valsartan would be efficacious in those with HFmrEF.

\section{OTHER THERAPEUTICS}

Digoxin had an intermediate effect on HFmrEF [HR: 0.80, 95\% CI (0.63-1.03)] compared with HFrEF and HFpEF, and did not significantly reduce HF hospitalization in the HFmrEF population (20). Diuretics seem to be negatively associated with improved mortality in HFmrEF (13). Sodium glucose cotransporter 2 inhibitors (SGLT-2I), an inhibitor of a new pathway of HF treatment different from the neurohormonal one, are associated with reduced HF hospitalizations and CV death in patients with type 2 diabetes mellitus regardless of history of HF $(24,25)$, and the ongoing EMPEROR-Preserved, DELIVER, and SOLOIST-WHF trials may confirm the effect of these drugs on HF outcomes in patients with LVEF $>45 \%$. The summary of the effect of the main HF therapies on outcomes specifically in the HFmrEF population is reported in Table 1.

HFmrEF is not a stable phenotype, but a heterogenous condition with variable evolutions, which is proven by the fact that without any change in underlying pathophysiology, a number of HF patients move in and out of the HFmrEF range on serial echocardiograms $(6,26)$. The treatment and management of coronary artery disease and atrial fibrillation seems to be important in the process of heart failure phenotype transition. As indicated by the HF Long-Term Registry of the European
Society of Cardiology (27), the prevalence of AF was higher with increasing LVEF (27\% in HFrEF, 29\% in HFmrEF, and $39 \%$ in $\mathrm{HFpEF}$ ) and $\mathrm{AF}$ was associated with worse outcomes (combined HF hospitalization and all-cause mortality) in HFpEF $[\mathrm{HR}=1.36,95 \% \mathrm{CI}(1.15-1.62), p<0.001]$ and HFmrEF $[\mathrm{HR}=1.30,95 \% \mathrm{CI}(1.06-1.61), p=0.014]$, but not in HFrEF $[\mathrm{HR}=0.96,95 \% \mathrm{CI}(0.84-1.09), p=0.502]$. In the SwedeHF trial (6), HFmrEF resembled HFrEF most notably for CAD (HFrEF $54 \%$, HFmrEF 53\%, HFpEF 42\%, $p<0.001$ ), and notable adjusted odds ratios (ORs) were similar for CAD [HFmrEF vs. HFpEF: OR 1.52, 95\% CI (1.41-1.63); HFmrEF vs. HFrEF: OR 0.94, 95\% CI (0.88-1.00)]. Although targeting patients of HFmrEF specifically, like we did in other HF groups, is efficacious for resolving questions that disturbed us, many have failed due to the difficulties in patient enrollment. In addition, the variability of LVEF measurements based on echocardiography influences the accuracy of EF evaluation. Potential solutions to these issues might include the following: (1) expanding the EF range of HFrEF and/or HFpEF to include HFmrEF or the entire EF spectrum, as we did in some research evaluating ARB, MRA, and ARNI therapy in HFmrEF, and (2) evaluating EF in a dynamic and serial way, as beyond evaluating baseline LVEF, the implications of longitudinal LVEF are becoming more important.

In the era of precision medicine, the future management of HFmrEF or HF patients may involve accurately evaluating cardiac function and identifying features of each patient with HF, which might provide us with more information about how to scientifically stratify risk factors and choose appropriate therapies beyond what is predicted by LVEF alone, help doctors discern true myocardial recovery from myocardial remission which includes reverse cardiac remolding, but the absence of signs of complete reversal of damage, and multiparametric approaches, such as biomarkers and image parameters, should be taken into account for the discovery of new more effective treatments.

\section{CONCLUSION}

The expanding insights of HFmrEF indicate to us that it is an intermediate phenotype between HFrEF and HFpEF in terms of baseline characteristics, outcomes, and prognosis, but mildly resembles more that of the HFrEF subtype than HFpEF. As summarized in Table 2, ARB, beta-blockers, MRA, and ARNI may have potential cardiovascular benefits for patients with HFmrEF, but it is uncertain whether ACEI or SGLT-2I has 
cardiovascular benefits. Future research, especially RCTs, is needed to explore the expanding insights into this peculiar phenotype and to identify strategies that will best achieve improvements in cardiovascular outcomes.

\section{REFERENCES}

1. Paulus WJ, Tschöpe, C. A novel paradigm for heart failure with preserved ejection fraction: comorbidities drive myocardial dysfunction and remodeling through coronary microvascular endothelial inflammation. J Am Coll Cardiol. (2013) 62:263-71. doi: 10.1016/j.jacc.2013.02.092

2. Yancy CW, Jessup M, Bozkurt B, Butler J, Casey DE, Jr., Drazner MH, et al. 2013 ACCF/AHA guideline for the management of heart failure: a report of the American College of Cardiology Foundation/American Heart Association Task Force on practice guidelines. Circulation. (2013) 128:240327. doi: 10.1161/CIR.0b013e31829e 8776

3. Ponikowski P, Voors AA, Anker SD, Bueno H, Cleland JGF, Coats AJS, et al. 2016 ESC Guidelines for the diagnosis treatment of acute chronic heart failure: The Task Force for the diagnosis treatment of acute chronic heart failure of the European Society of Cardiology (ESC) developed with the special contribution of the Heart Failure Association (HFA) of the ESC. Eur Heart J. (2016) 37:2129-200. doi: 10.1093/eurheartj/ehw128

4. Rickenbacher P, Kaufmann BA, Maeder MT, Bernheim A, Goetschalckx K, Pfister O, et al. Heart failure with mid-range ejection fraction: a distinct clinical entity? Insights from the trial of intensified versus standard medical therapy in elderly patients with congestive heart failure (TIME-CHF). Eur $J$ Heart Fail. (2017) 19:1586-96. doi: 10.1002/ejhf.798

5. Chioncel O, Lainscak M, Seferovic PM, Anker SD, Crespo-Leiro MG, Harjola VP, et al. Epidemiology and one-year outcomes in patients with chronic heart failure and preserved, mid-range and reduced ejection fraction: an analysis of the ESC heart failure long-term registry. Eur J Heart Fail. (2017) 19:1574-85. doi: 10.1002/ejhf.813

6. Koh AS, Tay WT, Teng THK, Vedin O, Benson L, Dahlstrom U, et al. A comprehensive population-based characterization of heart failure with mid-range ejection fraction. Eur J Heart Fail. (2017) 19:162434. doi: 10.1002/ejhf.945

7. Lupón J, Díez-López C, De Antonio M, Domingo M, Zamora E, Moliner P, et al. Recovered heart failure with reduced ejection fraction and outcomes: a prospective study. Eur J Heart Fail. (2017) 19:1615-23. doi: 10.1002/ejhf.824

8. Savarese G, Vedin O, D’amario D, Uijl A, Dahlström U, Rosano G, et al. Prevalence and prognostic implications of longitudinal ejection fraction change in heart failure. JACC Heart Fail. (2019) 7:306-17. doi: 10.1016/j.jchf.2018.11.019

9. Lund LH, Claggett B, Liu J, Lam CS, Jhund PS, Rosano GM, et al. Heart failure with mid-range ejection fraction in CHARM: characteristics, outcomes and effect of candesartan across the entire ejection fraction spectrum. Eur J Heart Fail. (2018) 20:1230-9. doi: 10.1002/ejhf.1149

10. Massie BM, Carson PE, Mcmurray JJ, Komajda M, Mckelvie R, Zile MR, et al. Irbesartan in patients with heart failure and preserved ejection fraction. $N$ Engl J Med. (2008) 359:2456-67. doi: 10.1056/NEJMoa0805450

11. Fonarow GC, Stough WG, Abraham WT, Albert NM, Gheorghiade M, Greenberg BH, et al. Characteristics, treatments, and outcomes of patients with preserved systolic function hospitalized for heart failure: a report from the OPTIMIZE-HF registry. J Am Coll Cardiol. (2007) 50:76877. doi: 10.1016/j.jacc.2007.04.064

12. Cleland JGF, Bunting KV, Flather MD, Altman DG, Holmes J, Coats AJS, et al. Beta-blockers for heart failure with reduced, midrange, and preserved ejection fraction: an individual patient-level analysis of double-blind randomized trials. Eur Heart J. (2018) 39:26-35. doi: 10.1093/eurheartj/ehx564

13. Tsuji K, Sakata Y, Nochioka K, Miura M, Yamauchi T, Onose T, et al. Characterization of heart failure patients with mid-range left ventricular ejection fraction-a report from the CHART-2 Study. Eur J Heart Fail. (2017) 19:1258-69. doi: 10.1002/ejhf.807

14. Hernandez AF, Hammill BG, O'connor CM, Schulman KA, Curtis LH, Fonarow, et al.C. Clinical effectiveness of beta-blockers in heart failure: findings from the OPTIMIZE-HF (organized program to initiate lifesaving

\section{AUTHOR CONTRIBUTIONS}

All authors listed have made a substantial, direct and intellectual contribution to the work, and approved it for publication.

treatment in hospitalized patients with heart failure) registry. J Am Coll Cardiol. (2009) 53:184-92. doi: 10.1016/j.jacc.2008.09.031

15. Patel K, Fonarow GC, Ekundayo OJ, Aban IB, Kilgore ML, Love TE, et al. Beta-blockers in older patients with heart failure and preserved ejection fraction: class, dosage, and outcomes. Int J Cardiol. (2014) 173:393401. doi: 10.1016/j.ijcard.2014.03.005

16. Solomon SD, Claggett B, Lewis EF, Desai A, Anand I, Sweitzer NK, et al. Influence of ejection fraction on outcomes and efficacy of spironolactone in patients with heart failure with preserved ejection fraction. Eur Heart J. (2016) 37:455-62. doi: 10.1093/eurheartj/ehv464

17. Enzan N, Matsushima S, Ide T, Kaku H, Higo T, Tsuchihashi-Makaya M, et al. Spironolactone use is associated with improved outcomes in heart failure with mid-range ejection fraction. ESC Heart Fail. (2020) 7:33947. doi: 10.1002/ehf2.12571

18. Solomon SD, Mcmurray JJV, Anand IS, Ge J, Lam CSP, Maggioni AP, et al. Angiotensin-Neprilysin inhibition in heart failure with preserved ejection fraction. N Engl J Med. (2019) 381:1609-20. doi: 10.1056/NEJMoa1908655

19. Solomon SD, Vaduganathan M, B LC, Packer M, Zile M, Swedberg K, et al. Sacubitril/valsartan across the spectrum of ejection fraction in heart failure. Circulation. (2020) 141:35261. doi: 10.1161/CIRCULATIONAHA.119.044586

20. Abdul-Rahim AH, Shen L, Rush CJ, Jhund PS, Lees KR, Mcmurray JV, et al. Effect of digoxin in patients with heart failure and mid-range (borderline) left ventricular ejection fraction. Eur J Heart Fail. (2018) 20:113945. doi: 10.1002/ejhf.1160

21. Jering KS, Zannad F, Claggett B, Mc Causland FR, Ferreira JP, Desai $A$, et al. Cardiovascular and renal outcomes of mineralocorticoid receptor antagonist use in PARAGON-HF. JACC Heart Fail. (2021) 9:13-24. doi: 10.1016/j.jchf.2020.08.014

22. Wachter R, Shah SJ, Cowie MR, Szecsödy P, Shi V, Ibram G, et al. Angiotensin receptor neprilysin inhibition versus individualized RAAS blockade: design and rationale of the PARALLAX trial. ESC Heart Fail. (2020) 7:85664. doi: 10.1002/ehf2.12694

23. Spannella F, Giulietti F, Filipponi A, Sarzani, R. Effect of sacubitril/valsartan on renal function: a systematic review and meta-analysis of randomized controlled trials. ESC Heart Fail. (2020) 7:3487-96. doi: 10.1002/ehf2.13002

24. Wiviott SD, Raz I, Bonaca MP, Mosenzon O, Kato ET, Cahn A, et al. Dapagliflozin and cardiovascular outcomes in type 2 diabetes. $N$ Engl J Med. (2019) 380:347-57. doi: 10.1056/NEJMoa1812389

25. Zinman B, Wanner C, Lachin JM, Fitchett D, Bluhmki E, Hantel S, et al. Empagliflozin, cardiovascular outcomes, and mortality in type 2 diabetes. $N$ Engl J Med. (2015) 373:2117-28. doi: 10.1056/NEJMoa1504720

26. Rastogi A, Novak E, Platts AE, Mann, D.L. Epidemiology, pathophysiology and clinical outcomes for heart failure patients with a mid-range ejection fraction. Eur J Heart Fail. (2017) 19:1597-605. doi: 10.1002/ ejhf.879

27. Zafrir B, Lund LH, Laroche C, Ruschitzka F, Crespo-Leiro MG, et al. Prognostic implications of atrial fibrillation in heart failure with reduced, mid-range, and preserved ejection fraction: a report from 14964 patients in the European Society of Cardiology Heart Failure Long-Term Registry. Eur J Heart Fail. (2018) 39:4277-84. doi: 10.1093/eurheartj/ehy626

Conflict of Interest: The authors declare that the research was conducted in the absence of any commercial or financial relationships that could be construed as a potential conflict of interest.

Copyright $\odot 2021 \mathrm{Ma}$, Su, Song and Xu. This is an open-access article distributed under the terms of the Creative Commons Attribution License (CC BY). The use, distribution or reproduction in other forums is permitted, provided the original author(s) and the copyright owner(s) are credited and that the original publication in this journal is cited, in accordance with accepted academic practice. No use, distribution or reproduction is permitted which does not comply with these terms. 